\title{
THE
}

$11-2008$

\section{Spatial Density Dependence Scales up but Does Not Produce Temporal Density Dependence in a Reef Fish}

\author{
Graham E. Forrester \\ University of Rhode Island, gforrester@uri.edu \\ Mark A. Steele \\ Jameal F. Samhouri \\ Bryn Evans \\ Richard R. Vance
}

Follow this and additional works at: https://digitalcommons.uri.edu/nrs_facpubs

Terms of Use

All rights reserved under copyright.

\section{Citation/Publisher Attribution}

Forrester, G. E., Steele, M. A., Samhouri, J. F., Evans, B. and Vance, R. R. (2008), SPATIAL DENSITY

DEPENDENCE SCALES UP BUT DOES NOT PRODUCE TEMPORAL DENSITY DEPENDENCE IN A REEF

FISH. Ecology, 89: 2980-2985. doi:10.1890/07-1546.1

Available at: http://dx.doi.org/10.1890/07-1546.1

This Article is brought to you for free and open access by the Natural Resources Science at DigitalCommons@URI. It has been accepted for inclusion in Natural Resources Science Faculty Publications by an authorized administrator of DigitalCommons@URI. For more information, please contact digitalcommons-group@uri.edu. 


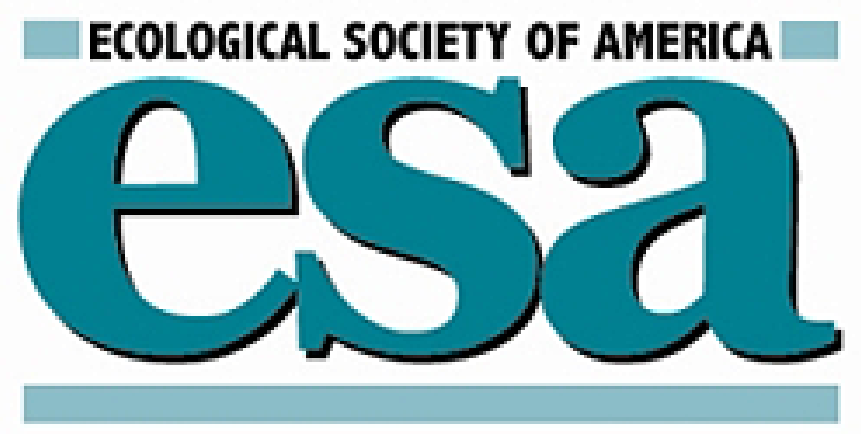

Spatial Density Dependence Scales up but Does Not Produce Temporal Density Dependence in a Reef Fish

Author(s): Graham E. Forrester, Mark A. Steele, Jameal F. Samhouri, Bryn Evans and Richard R. Vance

Source: Ecology, Vol. 89, No. 11 (Nov., 2008), pp. 2980-2985

Published by: Ecological Society of America

Stable URL: http://www.jstor.org/stable/27650853

Accessed: $21 / 03 / 201312: 15$

Your use of the JSTOR archive indicates your acceptance of the Terms \& Conditions of Use, available at http://www.jstor.org/page/info/about/policies/terms.jsp

JSTOR is a not-for-profit service that helps scholars, researchers, and students discover, use, and build upon a wide range of content in a trusted digital archive. We use information technology and tools to increase productivity and facilitate new forms of scholarship. For more information about JSTOR, please contact support@jstor.org. 


\title{
SPATIAL DENSITY DEPENDENCE SCALES UP BUT DOES NOT PRODUCE TEMPORAL DENSITY DEPENDENCE IN A REEF FISH
}

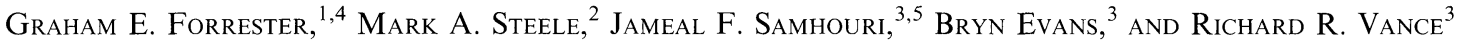 \\ ${ }^{1}$ Department of Natural Resources Science, University of Rhode Island, Kingston, Rhode Island 02881 USA \\ ${ }^{2}$ Department of Biology, California State University-Northridge, 18111 Nordhoff Street, Northridge, California $91330-8303$ USA \\ ${ }^{3}$ Department of Ecology and Evolutionary Biology, University of California, Los Angeles, California 90095-1606 USA
}

Abstract. Field experiments provide rigorous tests of ecological hypotheses but are typically of short duration and use small spatial replicates. We assessed empirically whether the results of experiments testing for density dependence applied at larger spatial domains and explained temporal population dynamics. We studied a small coral reef fish, the goldspot goby (Gnatholepis thompsoni), in the Bahamas. We assessed the effects of interactions with conspecifics and with an ecologically similar species, the bridled goby (Coryphopterus glaucofraenum). Two density manipulations on small reef patches revealed that goldspot goby mortality over one month increased as conspecifics became crowded. On five large natural reefs, we correlated the initial year-class density of both species (annual larval settlement) with the subsequent decline of goldspot goby year-classes for five years. Mortality was correlated with conspecific density among reefs for all years, but not among years for all reefs. Thus, spatial density dependence in mortality scaled up qualitatively from small patches to entire reefs but was not associated with temporal density dependence. Our results support the conclusion that field experiments may be extrapolated to larger spatial domains with care, but that using small spatial comparisons to predict temporal responses is difficult without knowing the underlying biological mechanisms.

Key words: coral reefs; density dependence; field experiments; fish; mortality; spatial scaling; temporal density dependence.

\section{INTRODUCTION}

Temporal density dependence is necessary for population size to be regulated within bounds over time (Murdoch 1994). That is, as a population increases in density through time its per capita rate of growth must decrease. For many groups of animals, density dependence has been assessed primarily by analyzing time series of abundance (e.g., Brook and Bradshaw 2006), which presents a variety of methodological challenges (e.g., Shenk et al. 1998). Experimental manipulation of density is a more direct method to test for density dependence but is often difficult in nature (Harrison and Cappuccino 1995). The field experiments conducted to date have been particularly valuable in testing for density dependence that could lead to such population regulation and in identifying its underlying biological causes (Harrison and Cappuccino 1995). Most such studies, however, have focused on spatial density dependence, which does not necessarily lead to temporal density dependence (Stewart-Oaten and Murdoch 1990), and the populations studied have typically occupied

Manuscript received 19 September 2007; revised 27 February 2008; accepted 19 May 2008. Corresponding Editor: S. R. Thorrold.

${ }^{4}$ E-mail: gforrester@uri.edu

${ }^{5}$ Present address: Northwest Fisheries Science Center, National Marine Fisheries Service, 2725 Montlake Boulevard East, Seattle, Washington 98112 USA. small patches of habitat. Given the possibility that the intensity of density dependence may change as spatial scale increases (e.g., Chesson 1996), it is unclear whether the results of these small-scale studies can be extrapolated to scales more relevant to management and conservation.

Reef fishes are excellent subjects for experimental tests of density dependence because they are easily observed and manipulated in situ. Such studies have been particularly valuable in demonstrating the prevalence of spatial density dependence across small habitat patches (reviewed in Hixon and Webster 2002, Osenberg et al. 2002), and more recently in identifying the causes of this density dependence (e.g., Hixon and Carr 1997, Carr et al. 2002, Holbrook and Schmitt 2002, Forrester and Steele 2004). The habitat patches used for these studies are almost always less than $10 \mathrm{~m}^{2}$ in area, and only two recent studies have tested whether spatial density dependence extrapolates to spatial domains relevant to conservation and management (Steele and Forrester 2005, Johnson 2006). Moreover, there is only limited evidence that the spatial density dependence detected in reef fishes translates to temporal density dependence that can regulate populations (Webster 2003, Steele and Forrester 2005, Johnson 2006, Schmitt and Holbrook 2007). We used an abundant coral reef fish to determine whether density dependence clearly present in small habitat patches also occurs on much 
larger reefs at any one time and over multiple years on any one reef. We examined effects of conspecific density and the density of a potentially competing species to infer the biological cause of density dependence, and to address possible reasons for its extension, or lack thereof, through space and through time.

\section{METHODS}

\section{The study species}

We studied the goldspot goby Gnatholepis thompsoni, a small coral reef fish common throughout the wider Caribbean. Our study sites were located on the Great Bahama Bank near Lee Stocking Island $\left(23^{\circ} 46^{\prime} \mathrm{N}\right.$, $\left.76^{\circ} 10^{\prime} \mathrm{W}\right)$. Goldspot gobies are pelagic as larvae for $\sim 45-80$ days and settle to reefs nightly from June through September (M. Steele, unpublished data). The gobies are $\sim 9-12 \mathrm{~mm}$ standard length (SL, the length from the tip of the snout to the base of the tail) at settlement, become mature by $25 \mathrm{~mm} \mathrm{SL}$, and reach a maximum size of $\sim 60 \mathrm{~mm}$ SL. Subadult and adult abundance peaks at roughly $4.5 \mathrm{fish} / \mathrm{m}^{2}$ in late October, when the summer's settlers have reached sizes of 20-40 $\mathrm{mm}$. From late October, abundance steadily declines until the next settlement season, and few individuals live longer than one year (M. Steele and G. Forrester, unpublished data).

On the reef, goldspot gobies establish small $\left(<5 \mathrm{~m}^{2}\right)$ stable home ranges that typically overlap with those of conspecifics. Gobies occupy reefs where sand and hard substrata are interspersed, because they feed on invertebrates in the sand but seek temporary refuge from predators in crevices at the base of corals or rocks when threatened or attacked. Goldspot goby habitat preferences resemble those of the bridled goby (Coryphopterus glaucofraenum), and home ranges of the two species often overlap (M. Steele and G. Forrester, unpublished data). Because bridled gobies compete intraspecifically for crevices (Forrester and Steele 2004), we assessed whether intra- or inter-specific competition for refuges might cause density-dependent mortality in goldspot gobies.

Small-scale spatial density dependence in adult mortality

We performed two density manipulations to test for density-dependent adult mortality. The experiments were performed in July-August of 1999 and 2000. These experiments employed the same set of replicate patch reefs and used similar methods. The 24 patch reefs were built in a shallow sandy area near a large natural reef (Rainbow Reef). Reefs were made of natural materials (limestone, coral rubble, and conch shells) in standardized amounts. All reefs were approximately $1.5 \times 1.5 \mathrm{~m}$ in length, and were located at least $10 \mathrm{~m}$ from each other and at least $23 \mathrm{~m}$ from Rainbow Reef.

We used a form of response surface design to isolate the relative effects of conspecific and heterospecific density (Inouye 2001). Some reefs were stocked only with goldspot gobies, whereas others received a mix of goldspot and bridled gobies (Appendix A). To test qualitatively whether density dependence arises from a shortage of crevices, we added rubble and shells to the reefs in 2000. If density dependence is caused by competition for refuges, it should thus be weaker in 2000 than in 1999.

Adult gobies of both species (25-35 mm SL in 1999 and $23-45 \mathrm{~mm}$ SL in 2000) were captured from natural habitat $2 \mathrm{~km}$ away and transplanted to the patch reefs after being measured and marked. Marks were spots of colored elastomer (Northwest Marine Technology, Shaw Island, Washington, USA) injected under the skin at various locations on the gobies' bodies to create unique codes (Malone et al. 1999). Divers can read these marks without recapturing the gobies. Gobies were transplanted at least two days before the start of the experiment to allow acclimation to their surroundings. During acclimation, they were protected from predators by a plastic cage (5-mm mesh size) placed over the reef.

The experiments began upon cage removal and lasted 28-31 days in 1999 and 35 days in 2000. The reefs were censused every 1-3 days for the first two weeks after cage removal and every 5-10 days thereafter. In addition to surveying the patch reefs, we surveyed nearby portions of Rainbow Reef to check for emigrants. At the end of the experiment, we captured all gobies on the patch reefs to identify any that had been missed during the visual counts. As the experiment progressed, we attempted to maintain initial target densities by either removing untagged immigrants from reefs, or transplanting new individuals. Despite these adjustments, densities fluctuated slightly during the experiment, and we used time-averaged densities when testing for density dependence. The range of time-averaged densities (adults per $\mathrm{m}^{2}$ ) on the reefs extended beyond the natural range (0-4.5) in $1999(0.09-7.82)$, but not in $2000(0.36$ 3.50). Although all adult gobies on the reefs were included in density estimates, only tagged gobies present from the start of the experiment were used to estimate mortality rates. The instantaneous per capita mortality rate $(m)$, with time measured in days, was estimated from the initial $(I)$ and final $(F)$ density of marked gobies on a reef as

$$
m=[\ln (I)-\ln (F)] / d
$$

where $d$ is the number of days between the start and the end of the experiment.

\section{Large-scale spatial and temporal density dependence in adult mortality}

We performed an observational study over five years (1998-2001 and 2003) to test for a large-scale correlation between goby density and mortality. We studied the gobies on five large natural reefs spread over $25 \mathrm{~km}$. Each reef contained $3000-15000 \mathrm{~m}^{2}$ of goby habitat and was isolated from any other suitable habitat by at least $100 \mathrm{~m}$ of sand and seagrass. After settlement, gobies do not move among reefs this far apart (M. Steele, 
unpublished data), and so we are confident that losses occurred only by deaths.

Each year, we monitored settlement to the five sites for most of the settlement season, though the duration (7-12 weeks) and timing (start dates 8 June-11 July; end dates 26 August-13 September) of the sampling period varied from year to year. We used a method previously shown to provide good estimates of cumulative daily settlement (for details see Steele and Forrester 2002). Briefly, newly settled gobies were collected weekly from five plots $(1.5 \times$ $1.5 \mathrm{~m}$ in area) on each reef that were located in a stratified random fashion. Plots were enclosed with cages of plastic mesh (5-mm openings) that were permeable to settling gobies but excluded larger fishes that prey on them. When testing for density dependence, we used a simple time-averaged measure of settler density (no. settlers $\mathrm{m}^{-2} \cdot \mathrm{wk}^{-1}$ ) that reflects relative differences in year-class strength among sites and years.

We estimated the density of adult and sub-adult gobies in late October when their abundance was at its annual peak. Divers counted gobies within $251.5 \times 1.5 \mathrm{~m}$ quadrats per site that had been placed using a stratified, random design. The standard length of each goby was estimated visually, and each goby was assigned to one of nine $5 \mathrm{~mm}$ wide size classes. (Prior trials with over 200 captured gobies had revealed that visual length estimates were always accurate within $2 \mathrm{~mm}$ of actual size.) To determine which gobies were survivors from the summer's settlement, we used a statistical relationship between length and age ( $n>60$ per site), derived from analysis of otolith growth rings (M. Steele, unpublished data).

The instantaneous per capita mortality rate was estimated separately for each site in each year. For simplicity, we assumed that each weekly settler cohort arrived at exactly the midpoint of the week in which it was collected. Let $t_{i}$ represent the middle day of the $i$ th week, $x_{t_{i}}$ represent the estimated density of individuals that settled on the reef during week $i$, and $X_{T}$ the density of gobies in all cohorts combined that remained on the day $T$ of the October count. Then, assuming that all individuals experience the same instantaneous per capita mortality rate $m$ (Caley 1998), it follows that these quantities are related by the expression

$$
X_{T}=\sum_{i=1}^{i_{\max }} x_{t_{i}} e^{-m\left(T-t_{i}\right)}
$$

where $i_{\max }$ is the number of weekly cohorts. We used this expression to calculate $m$ from the other quantities iteratively.

\section{Estimating the strength of density dependence}

We tested for the presence and strength of density dependence by using linear regression or analysis of covariance (ANCOVA). In both the experimental and observational studies, we tested for possible competition between goldspot gobies and bridled gobies by comparing regression or ANCOVA models that contained terms

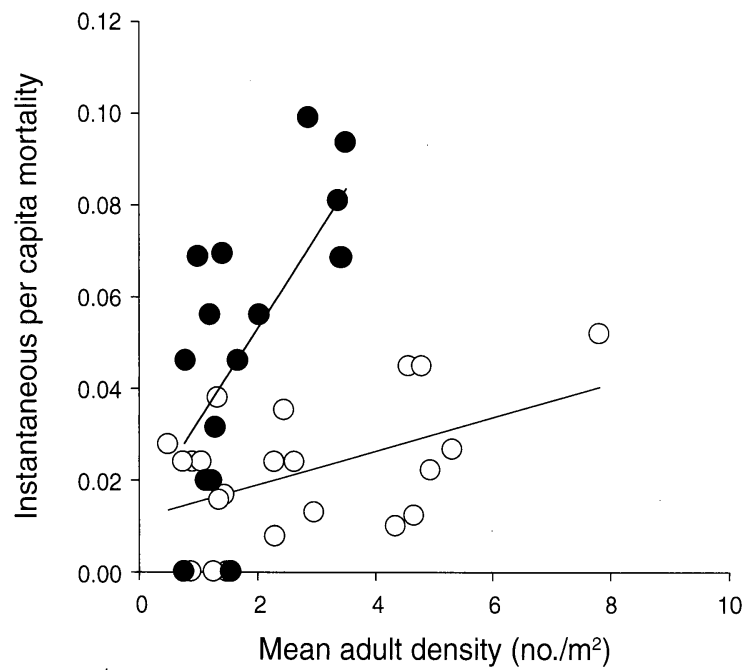

Fig. 1. Small-scale spatial density dependence in adult mortality. Plotted are relationships between instantaneous per capita mortality of adult gobies (calculated on a daily basis) and time-averaged adult density on small replicate patch reefs. Adult density was manipulated in two experiments: the first in 1999 (black symbols) and the second in 2000 (open symbols).

for conspecific density only, heterospecific density only, and the summed density of both gobies. The strength of density dependence was measured as the slope $(b)$ of the best-fit relationship between mortality and density. For the large-scale observational study, the data were analyzed with ANCOVA in two different ways: one to test for spatial density dependence and one to test for temporal density dependence. To test for spatial density dependence, data were grouped by year so the ANCOVA model included terms for effects of settler density (a covariate) and differences among years (a categorical factor) and their interaction. To test for temporal density dependence, data were grouped by site, so the ANCOVA model included terms for effects of settler density, differences among sites (a categorical factor) and their interaction. There were no significant effects of the categorical factors or interactions in the ANCOVAs $(P$ always $>0.05$ ) and, because they are of less interest than influences of density, we will not describe them further.

\section{REsUlts}

Small-scale spatial density dependence in adult mortality

In both small-scale experiments, mortality of adult goldspot gobies increased significantly with conspecific density (regression for 1999, $r^{2}=0.19, P=0.019$; regression for $2000, r^{2}=0.51, P=0.001$; Fig. 1). The strength of this density dependence, however, was almost six times less in the 1999 than in 2000 (regression for 1999, $m=0.0037$; regression for 2000, $m=0.0214$ ). As the number of crevices usable as refuges from predators was greater in 2000 than in 1999, the direction of this difference is opposite to the expectation if refuge shortage were the cause of density dependence. 


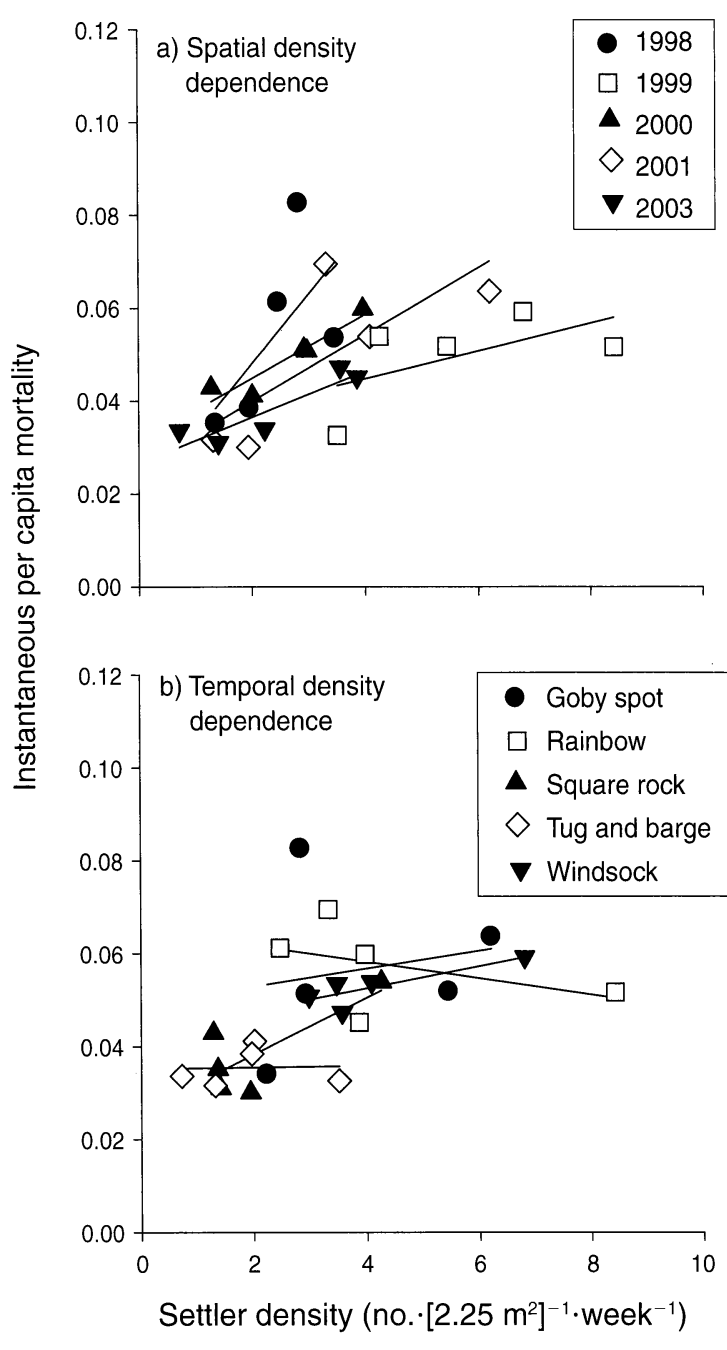

FIG. 2. Large-scale spatial and temporal density dependence in overall mortality. Plotted are relationships between instantaneous per capita mortality of gobies from settlement to adulthood (calculated on a daily basis) and time-averaged settler density on five large reefs. Data are (a) grouped by year to test for spatial density dependence and (b) grouped by site to test for temporal density dependence. Regression lines are displayed separately by (a) year or (b) site as a visual guide; see Results: Large-scale spatial and temporal density dependence in mortality for the results of statistical analyses.

We found no evidence that mortality of goldspot gobies was influenced by bridled goby density. Goldspot goby mortality was unrelated to the density of either bridled gobies alone (regression for 1999, $r^{2}=0.03, P=$ 0.209 ; regression for $2000, r^{2}=0.01, P=0.326$ ) or both species combined (regression for 1999, $r^{2}=0.01, P=$ 0.837; regression for 2000, $r^{2}=0.12, P=0.099$ ).

\section{Large-scale spatial and temporal density dependence in mortality}

The large-scale observations of goldspot goby density and mortality revealed significant spatial density dependence (Fig. 2a). The ANCOVA detected a significant increase in mortality with rising conspecific density $\left(F_{1,19}\right.$ $=13.2, P=0.002)$. The strength of density dependence varied fivefold among years, but these differences were not statistically significant $\left(F_{4,15}=0.80, P=0.55\right)$. Fluctuations in density of the two goby species were positively correlated spatially so that, in all years, certain sites supported consistently high or low densities of both species (Appendix B). This spatial covariance of the two gobies made it difficult to isolate their relative effects on goldspot goby mortality, and we obtained qualitatively similar results from ANCOVAs in which the original independent variable (goldspot goby density) was replaced by either bridled goby density or the combined density of both species. In each case, there was a significant positive relationship between goldspot goby mortality and density (ANCOVA using bridled goby density, $F_{1,15}=9.8, P=0.007$; ANCOVA using combined density, $F_{1,15}=17.98, P=0.001$ ).

This same large-scale study revealed no evidence for temporal density dependence (Fig. 2b). There was no consistent tendency for goldspot goby mortality rates to be higher in years when conspecific densities were high $\left(F_{1,19}=0.37, P=0.550\right)$. Although densities of the two gobies covaried spatially, there was little temporal correlation between them. That is, "high-" or "low-" density years for bridled gobies did not coincide with high- or low-density years for goldspot gobies (Appendix B). This lack of temporal correlation provides an opportunity to isolate the relative effects of conspecific and heterospecific density on goldspot goby mortality. However, replacing the original independent variable (goldspot goby density) with either bridled goby density or the combined density of both species produced no detectable effects on goldspot goby mortality (ANCOVA using bridled goby density, $F_{1,15}=0.26, P=0.616$ ANCOVA using combined density, $F_{1,15}=0.98, P=$ $0.338)$.

\section{Discussion}

Our finding that spatial density dependence in the goldspot goby was detectable both in small habitat patches and also across much larger natural reefs mirrors findings for two other reef fishes, the bridled goby and the kelp rockfish (Sebastes atrovirens) (Steele and Forrester 2005, Johnson 2006). By contrast, studies on another reef fish (Doherty and Fowler 1994, Beukers and Jones 1998), several insects (e.g., Heads and Lawton 1983, Hassell et al. 1987), and marine invertebrates (e.g., McGrorty and GossCustard 1995) have revealed spatial density dependence at certain scales but not others. In addition to displaying spatial density dependence across a range of scales, bridled gobies and kelp rockfish also showed temporal density dependence on large reefs (Steele and Forrester 2005, Johnson 2006). The mortality of another reef fish, the yellowtail dascyllus (Dascyllus flavicaudus) also responded to both spatial and temporal fluctuations in density, but in this case on small reef patches (Schmitt and Holbrook 2007). This 
lack of demonstrated association between spatial density dependence and temporal density dependence in goldspot gobies thus stands in contrast to these other three fish species. This contrast is especially striking in view of the fact that bridled gobies and goldspot gobies are so similar biologically and were studied on the same reefs, at the same time, and using the same methods (Steele and Forrester 2005).

Identifying the underlying biological cause of density dependence can help predict whether short-term local spatial effects will extrapolate to larger areas or persist through time (e.g., Murdoch and Oaten 1975, Kawat 1997). It is well established that an aggregative response by specialist predators can cause spatially densitydependent mortality of their prey without also causing temporal density dependence (e.g., Stewart-Oaten and Murdoch 1990). However, goldspot gobies, like most small reef fishes, are consumed by a suite of generalist predators whose combined influence is unlikely to produce density-dependent mortality via aggregative response (Latto and Hassell 1988). It is noteworthy that a refuge shortage is either confirmed (Holbrook and Schmitt 2002, Forrester and Steele 2004, Schmitt and Holbrook 2007) or implicated (Johnson 2006) as the underlying biological mechanism for density dependence in the reef fishes whose mortality is linked to density fluctuations in both space and time. This mechanism for density dependence may thus be one whose effect through space implies a similar effect through time.

Because goldspot gobies and bridled gobies show similar habitat preferences, have overlapping home ranges, and seem to share several predators, we thought that goldspot goby mortality might be influenced by both conspecific and heterospecific density. Our first conjecture was that intra- and interspecific competition for refuges was the most likely cause of density dependence in goldspot gobies. For marine species with a dispersive pelagic phase early in their life history, oceanographic processes can set up patterns of covariation in larval settlement among species (e.g., Wing et al. 1998). Distinct spatial and temporal patterns in the initial density of benthic cohorts could influence the outcome of densitydependent interactions later in life, though this topic has been little studied (White 2007). For example, when settlement of two species covaries positively in space, as we saw for goldspot and bridled gobies, this should intensify spatial density dependence due to interspecific competition. If, however, the same two species show no temporal covariation in settlement, temporal density dependence ought to be weaker and harder to detect. We were able to reject this possibility in our study system, however, because we found no evidence that interspecific competition influences mortality.

The biological cause of density dependence in goldspot gobies thus remains incompletely understood, although prior work (Forrester et al. 2006) and the experimental results allow us to narrow the list of possible mechanisms to those involving conspecific density. Superficially, our results seem to contradict the view that limited refuges cause intraspecific competition, because the difference in the strength of density dependence between the two small-scale experiments was opposite to that expected under refuge shortage. However, because we did not survey predators, we cannot exclude the possibility that higher predator densities increased density dependence during the year we added refuges. Indeed, our unquantified field observations created the subjective impression that predator densities were higher during the second experiment. It thus remains possible that goldspot gobies compete for refuges chiefly with conspecifics. If so, then there must be subtle niche segregation between the two gobies that we have not recognized, and the simple characterization of refuges that we developed for bridled gobies (Forrester and Steele 2004) must not adequately describe refuge use for goldspot gobies. Finally, density dependence in goldspot gobies could also arise from competition for a resource other than refuges, especially one whose supply varies through time, or result from other temporally variable interactions between goldspot gobies and their predators, parasites, or diseases.

In summary, goldspot gobies provide an example of a species that experiences spatially density-dependent mortality that does not clearly lead to temporal density dependence, a theoretical possibility (Stewart-Oaten and Murdoch 1990) that has received relatively little empirical study. In this species, it is clear that agents of mortality whose effects are unrelated to population density also play a key role in driving population dynamics (Sale and Tolimieri 2000). Our findings add support to the conclusion that the small-scale field experiments typically conducted by ecologists to study density dependence, and possibly other processes, may be extrapolated to larger scales with care. Extrapolating the results of studies using spatial replicates to predict temporal responses, however, may be more risky, and requires a sound understanding of the underlying biological mechanisms.

\section{ACKNOWLEDGMENTS}

We thank M. Briya, S. Bull, L. Conway-Cranos, B. Finley, A. Hall, J. Heywood, C. Juhasz, J. Krug, A. LaBonte, K. Reinhold, J. Sausman, J. Schinske, S. Shopmeyer, J. Standish, J. Tallman, C. Tran, E. Tynes, J. Voss, D. Weisman, and C. Wormald for assistance in the field and laboratory, the staff at the Caribbean Marine Research Center for logistical support, and the reviewers for helpful comments on the manuscript. Financial support came from grants to the authors from the National Science Foundation (OCE 9618011/0096061 and OCE 0222087), NOAA-NURP (CMRC-99-CRGF-01-01A, CMRC01-PRGF-01-01A，CMRC-01-NRME-01-02A，CMRC-01NRME-01-03C, CMRC-03-NRME-01-04A), and the Perry Foundation.

\section{Literature Cited}

Beukers, J. S., and G. P. Jones. 1998. Habitat complexity modifies the impact of piscivores on a coral reef fish population. Oecologia 114:50-59. 
Brook, B. W., and C. J. A. Bradshaw. 2006. Strength of evidence for density dependence in abundance time series of 1198 species. Ecology 87:1445-1451.

Caley, M. J. 1998. Age-specific mortality rates in reef fishes: evidence and implications. Australian Journal of Ecology 23 241-245.

Carr, M. H., T. M. Anderson, and M. A. Hixon. 2002 Biodiversity, population regulation, and the stability of coralreef fish communities. Proceedings of the National Academy of Sciences (USA) 99:11241-11245.

Chesson, P. L. 1996. Matters of scale in the dynamics of populations and communities. Pages $353-368$ in R. B. Floyd, R. W. Sheppard, and P. J. De Barro, editors. Frontiers of population ecology. CSIRO Publishing, Melbourne, Australia.

Doherty, P. J., and A. J. Fowler. 1994. An empirical test of recruitment limitation in a coral reef fish. Science 263:935939

Forrester, G. E., B. Evans, M. A. Steele, and R. R. Vance 2006. Assessing the magnitude of intra- and interspecific competition in two coral reef fishes. Oecologia 148:632-640.

Forrester, G. E., and M. A. Steele. 2004. Predators, prey refuges, and the spatial scaling of density-dependent prey mortality. Ecology 85:1332-1342.

Harrison, S., and N. Cappuccino. 1995. Using densitymanipulation experiments to study population regulation. Pages 131-172 in N. Cappuccino and P. W. Price, editors. Population dynamics: new approaches and synthesis. Academic Press, San Diego, California, USA.

Hassell, M. P., T. R. E. Southwood, and P. M. Reader. 1987. The dynamics of the viburnum whitefly (Aleurotrachelus jelinekii): a case study of population regulation. Journal of Animal Ecology 56:283-300.

Heads, P. A., and J. H. Lawton. 1983. Studies on the natura enemy complex of the holly leaf-miner: the effects of scale on the detection of aggregative responses and the implications for biological control. Oikos 40:267-276.

Hixon, M. A., and M. H. Carr. 1997. Synergistic predation, density dependence, and population regulation in marine fish. Science 277:946-949.

Hixon, M. A., and M. S. Webster. 2002. Density dependence in marine fishes: coral-reef populations as model systems. Page 303-325 in P. F. Sale, editor. Coral reef fishes: dynamics and diversity in a complex ecosystem. Academic Press, San Diego, California, USA.

Holbrook, S. J., and R. J. Schmitt. 2002. Competition for shelter space causes density-dependent predation mortality in damselfishes. Ecology 83:2855-2868.

Inouye, B. D. 2001. Response surface experimental designs for investigating interspecific competition. Ecology 82:2696 2706.
Johnson, D. W. 2006. Density dependence in marine fish populations revealed at small and large spatial scales. Ecology 87:319-325.

Kawat, M. 1997. Exploitative competition and ecologically effective abundance. Ecological Modelling 94:125-137.

Latto, J., and M. P. Hassell. 1988. Generalist predators and the importance of spatial density dependence. Oecologia 77:375377.

Malone, J. C., G. E. Forrester, and M. A. Steele. 1999. Effects of subcutaneous microtags on the growth, survival, and vulnerability to predation of small reef fishes. Journal of Experimental Marine Biology and Ecology 237:243-253.

McGrorty, S., and J. D. GossCustard. 1995. Population dynamics of Mytilus edulis along environmental gradients: density-dependent changes in adult mussel numbers. Marine Ecology Progress Series 129:197-213.

Murdoch, W. W. 1994. Population regulation in theory and practice. Ecology 75:271-287.

Murdoch, W., and A. Oaten. 1975. Predation and population stability. Advances in Ecological Research 9:1-132.

Osenberg, C. W., C. M. St Mary, R. J. Schmitt, S. J. Holbrook, P. Chesson, and B. Byrne. 2002. Rethinking ecological inference: density dependence in reef fishes. Ecology Letters 5:715-721.

Sale, P. F., and N. Tolimieri. 2000. Density dependence at some time and place? Oecologia 124:166-171.

Schmitt, R. J., and S. J. Holbrook. 2007. The scale and cause of spatial heterogeneity in strength of temporal density dependence. Ecology 88:1241-1249.

Shenk, T. M., G. C. White, and K. P. Burnham. 1998. Sampling-variance effects on detecting density dependence from temporal trends in natural populations. Ecological Monographs 68:445-463.

Steele, M. A., and G. E. Forrester. 2002. Early postsettlement predation on three reef fishes: effects on spatial patterns of recruitment. Ecology 83:1076-1091.

Steele, M. A., and G. E. Forrester. 2005. Small-scale field experiments accurately scale up to predict density dependence in reef fish populations at large-scales. Proceedings of the National Academy of Sciences (USA) 102:13513-13516.

Stewart-Oaten, A., and W. W. Murdoch. 1990. Tempora consequences of spatial density dependence. Journal of Animal Ecology 59:1027-1045.

Webster, M. S. 2003. Temporal density dependence and population regulation in a marine fish. Ecology 84:623-628.

White, J. W. 2007. Spatially correlated recruitment of a marine predator and its prey shapes the large-scale pattern of density-dependent prey mortality. Ecology Letters 10:1054 1065.

Wing, S. R., L. W. Botsford, S. V. Ralston, and J. L. Largier. 1998. Meroplanktonic distribution and circulation in a coastal retention zone of the northern California upwelling system. Limnology and Oceanography 43:1710-1721.

\section{APPENDIX A}

Experimental design (Ecological Archives E089-171-A1)

\section{APPENDIX B}

Spatial and temporal associations between the time-averaged settler density of goldspot and bridled gobies (Ecological Archives E089-171-A2). 